\title{
Spatial conservation prioritization across multiple taxa promises more efficient protection of Japan's biodiversity
}

Joona Lehtomäki

Buntarou Kusumoto

Takayuki Shiono

Takayuki Tanaka

Yasuhiro Kubota

Atte Moilanen

\section{Video Abstract}

Keywords: Diversity and Distributions, University of the Ryukyus, conservation biogeography, island biogeography, multitaxon approach, protected area network, reserve design, spatial conservation prioritization, Zonation software, geohistory, palaeoclimate, biodiversity, anthropogenic pressure, habitat loss, Aichi Biodiversity Targets, Convention on Biological Diversity, surrogacy, evolutionary history, conservation planning, species richness

Posted Date: October 23rd, 2020

DOI: https://doi.org/10.21203/rs.3.rs-97502/v1

License: (c) (i) This work is licensed under a Creative Commons Attribution 4.0 International License. Read Full License 


\section{Abstract}

Islands are hotspots of biodiversity. But they're in danger. Human activities are disrupting the natural habitats of numerous island plant and animal species, causing them to degrade, fragment, or perish altogether. Including here, in the islands of Japan. In response, the Japanese government has recently committed to a $17 \%$ expansion of its network of protected areas, spaces such as national parks that support long-term conservation of biodiversity and natural resources. The proposed expansion is one of the common global strategic plans for biodiversity, specifically, the Aichi Biodiversity Targets. The problem is that experts have no comprehensive, ecologically justified way of determining which areas to include. Now, a team of researchers from Japan and Finland has devised an analytical framework that could make Japan's protected area expansion as efficient as possible. Traditionally, planners have relied on an intuitive approach: for each at-risk species, create an account of past losses, current major threats, and the cost effectiveness of conservation actions. It's a good approach for individual species. But it misses the complex ways that species interact, leaving pockets where protection is less than ideal. Instead, the international research team pursued a more balanced, multi-taxon approach. They first clarified patterns in biodiversity for all native Japanese amphibians, birds, freshwater fish, mammals, reptiles, and vascular plants - more than 6300 species in all. They then performed a conservation priority analysis to determine which areas should be designated protection areas for each taxon. Finally, and most importantly, they combined all that data into a single, mega-analysis that accounted for overlaps between species from the six taxonomic groups. The result was a map of what conservation looks like when operating near maximum efficiency. For each species type, the analysis revealed the areas that should be prioritized for conservation planning. Importantly, it also showed the gap in coverage of Japan's current protected area network. The current network accounts for about $9 \%$ of the country's land area, but on average protects only $10 \%$ of the areas where species are found. Fortunately, Japan's proposed $17 \%$ expansion offers much room to make improvements. If designed to cover the areas where conservation efforts are truly needed most, the expansion could double the species coverage of Japan's protected area network. More work is needed to refine the analysis, such as factoring in insects and conservation costs as that data becomes available. But the results are promising. Comprehensive, efficient, and balanced, this new approach to determining conservation priority could be a powerful way to boost current protection efforts. And, importantly, it contributes to the Post-2020 Global Biodiversity Framework, an international effort whose vision for biodiversity by the year 2050 is a world "living in harmony with nature". 